\title{
POTENSI LANSEKAP UNTUK PENGEMBANGAN EKOWISATA DI HUTAN \\ LINDUNG REGISTER 25 PEMATANG TANGGANG KABUPATEN TANGGAMUS
}

\section{LANDSCAPE POTENTION FOR ECOTOURIM DEVELOPMENT IN FOREST AREA REGISTER 25 KELUMBAYAN VILLAGE TANGGAMUS DISTRICT}

\author{
By :
}

\section{Bramsah dan Arief Darmawan}

Jurusan Kehutanan, Fakultas Pertanian, Universitas Lampung

Jl. Prof. Dr. Sumantri Brojonegoro No.1 Bandar Lampung, 35145

E-mail :m.bramsah@gmail.com

Phone : +6282280157543

\begin{abstract}
ABSTRAK
Hutan Lindung Register 25 merupakan kawasan hutan yang memiliki luas sekitar 3.380 hektar dan memiliki potensi lansekap berupa pemandangan indah, air terjun, dan keanekaragaman flora fauna yang dapat dikembangkan sebagai lokasi ekowisata. Ekowisata adalah suatu bentuk wisata yang berwawasan lingkungan melalui aktivitas yang berkaitan dengan alam.

Penelitian ini bertujuan untuk melakukan inventarisasi dan menganalisis potensi lansekap di Register 25 untuk pengembangan ekowisata. Metode yang digunakan adalah obervasi, wawancara serta dokumentasi. Pengambilan data lapangan dilakukan pada Bulan Desember 2015 dengan mencatat lokasi potensi wisata menggunakan GPS, pengambilan dokumen objek-objek lansekap yang dipandang menarik kemudian diujicobakan kepada kalangan masyarakat yaitu masyarakat di lokasi penelitian dan wisatawan yang berkunjung ke Pantai Pahawang, dokumentasi serta wawancara.

Hasil penelitian dianalisis secara deskriptif kualitatif dan disajikan dalam bentuk peta jalur wisata. Dari hasil penelitian diketahui bahwa Register 25 Pematang Tanggang terdapat potensi wisata berupa pemandangan Teluk Kiluan, Pantai Batu Suluh, Gunung Tanggang, beberapa air terjun yang memiliki keunikan dan keindahan serta jenis flora dan fauna yang dapat dijumpai di sepanjang jalur wisata. Penilaian wisatawan terhadap objek wisata tersebut yaitu $85,55 \%$ bagus, $13,89 \%$ sedang, $0,56 \%$ buruk. Berdasarkan penilaian tersebut maka objek wisata yang terdapat di hutan lindung Register 25 Pematang Tanggang Kab. Tanggamus termasuk berpotensi untuk dikembangkan menjadi ekowisata.
\end{abstract}

Kata kunci : Ekowisata, Lansekap, Potensi, Register 25

\section{ABSTRACT}

Register 25 is the forest area have located in the Tanggamus district with an area of 3,380 hectares and have landscape potentials such a natural landscape, waterfalls, biodiversity of flora and fauna that can be developed as an ecotourism location. Ecotourism is a tourism conception from environmental by the activities which related to the nature.

This research have a purposed to take inventory and analysis landscape potentionn in Register 25 for ecotourism development. The method used on this research are observation, interview and documentation. The data have taken on December 2015 by wrote the location of the potential tourism used the GPS, the document retrieval of landscape objects which are seen as interest object used to be a trial to people who be the visitors of Pahawang Island, documentation and interview. 
The results were analized by descriptively qualitative and served as map of the tourist track. From this research have known that register 25, Pematang Tanggang the tourism potential there are view of Teluk Kiluan, Batu Suluh beach,Tanggang Mountain, and some waterfall that have the uniquely and beauty and biodiversity of flora and fauna that can be found along in the tourist track. The valuation of tourist about that tourism objects are $85,55 \%$ is good, 13,89\% is average, and 0,56\% is bad. Based on that value the tourism objects there are in forest area Register 25 Pematang Tanggang, Tanggamus District included to potentially for the develop e a ecotourism.

Keywords : Ecotourism, Landscape, Potential, Register 25

\section{PENDAHULUAN}

Perkembangan dalam sektor kepariwisataan pada saat ini melahirkan konsep pengembangan pariwisata alternatif yang tepat dan secara aktif membantu menjaga keberlangsungan berbagai aspek. Penetapan sebagai kawasan hutan menjadi objek wisata alam merupakan salah satu upaya pemanfaatan sumber daya alam hayati dan ekosistemnya secara bijaksana sehingga tetap dapat mengusahakan sumber daya alam tersebut tetap lestari (Nugroho, 2011). Ekowisata merupakan salah satu produk pariwisata alternatif yang mempunyai tujuan seiring dengan pembangunan pariwisata berkelanjutan (Sudiarta, 2006).

Provinsi Lampung merupakan salah satu daerah tujuan wisata yang banyak memiliki objek wisata unggulan. Salah satu kawasan di Provinsi Lampung yang berpotensi untuk menjadi kawasan wisata alam namun belum diketahui keberadaannya oleh khalayak adalah di Register 25 Desa Negeri Kecamatan Kelumbayan Kabupaten Tanggamus. Kawasan ini berada di Kabupaten Tanggamus dengan luas 3.380 hektar dengan potensi lansekap alami yang indah, air terjun, keanekaragaman flora dan fauna yang dapat dikembangkan sebagai lokasi ekowisata. Khakhim (2008) mengemukakan bahwa keindahan suatu lansekap dapat dinikmati dengan mengamati pemandangannya melalui indera penglihatan.

Karena kurangnya pengelolaan, perhatian dari pemerintah, dan peran serta masyarakat terhadap potensi wisata, membuat potensi wisata yang ada di kawasan ini tidak dapat berkembang sebagaimana mestinya. Akses jalan yang kurang memadai menjadi kendala utama dalam pengembangan ekowisata ditambah lagi informasi tentang potensi objek wisata untuk calon wisatawan sangat minim. Penelitian ini bertujuan untuk (1) untuk menggali potensi lansekap yang dapat dikembangkan sebagai objek ekowisata pada Hutan Lindung Register 25 Desa Negeri Kecamatan Kelumbayan Kabupaten Tanggamus, dan (2) untuk mengidentifikasi persepsi dan partisipasi masyarakat dalam mendukung ekowisata.

\section{METODE PENELITIAN}

Penelitian ini dilaksanakan di Hutan Lindung Register 25 Desa Negeri Kecamatan Kelumbayan Kabupaten Tanggamus pada Bulan Desember 2015 (Gambar 1). Alat yang digunakan adalah handheld GPS, komputer, SIG, alat tulis, binokuler dan kamera. Objek penelitian adalah potensi lansekap berupa bentang alam dan air terjun serta persepsi dan partisipasi masyarakat sekitar Register 25 Desa Negeri Kecamatan Kelumbayan Kabupaten Tanggamus.

Penggalian potensi lansekap dilakukan dengan menggunakan metode observasi lapangan dan membuat titik-titik lokasi atau jalur wisata yang memiliki nilai lansekap alam yang indah dan objek yang berpotensi menjadi daya tarik bagi wisatawan. Pengamatan flora dilakukan dengan metode rapid assessment yaitu mencatat secara cepat dan akurat terkait jenis tumbuhan yang terdapat di sekitar lokasi penelitian. Sedangkan pengamatan satwa dilakukan dengan metode point sampling yaitu dengan menentukan 10 titik pengamatan pada 
lokasi penelitian. Dokumentasi meliputi pengambilan gambar lansekap, flora dan fauna serta objek yang berpotensi sebagai daya dukung dalam pengembangan ekowisata. Wawancara dilakukan kepada masyarakat di sekitar lokasi penelitian dengan metode tidak terstruktur untuk mengetahui persepsi dan bentuk partisipasi masyarakat terhadap potensi objek ekowisata. Sedangkan wawancara kepada wisatawan dilakukan terhadap 30 responden untuk mengetahui penilaian terhadap potensi objek wisata alam.

Data yang diperoleh dari pengamatan dianalisis secara deskriptif kualitatif yaitu peneliti menguraikan, menjelaskan secara sistematis data hasil penelitian secara terperinci tentang keadaan dan potensi objek wisata tersebut. Selanjutnya data disajikan dalam bentuk peta jalur potensi ekowisata dengan menggunakan aplikasi SIG.

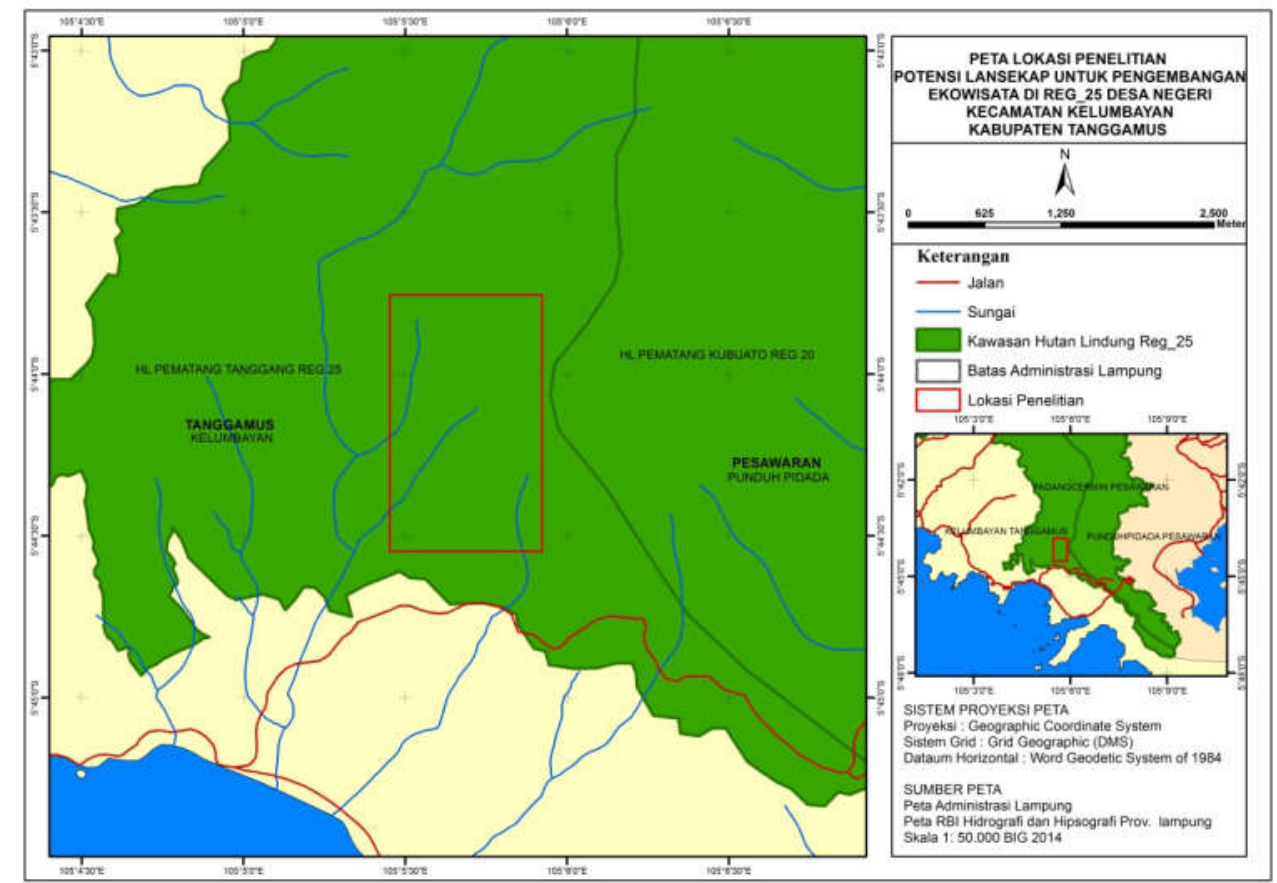

Gambar 1.Peta lokasi penelitian hutan lindung di Register 25 Pematang Tanggang Desa Negeri Kecamatan Kelumbayan Kabupaten Tanggamus.

\section{HASIL DAN PEMBAHASAN}

Potensi lansekap merupakan panorama alam dan air terjun, panorama alam yang dapat menjadi destinasi wisata di Register 25 Pematang Tanggang adalah panorama lepas Teluk Kiluan, Pantai Batu Suluh dan Gunung Tanggang. Selain itu terdapat objek wisata air terjun yang memiliki keunikan dan keindahan serta jenis flora dan fauna yang dapat dijumpai di sepanjang jalur wisata, seperti terlihat pada Gambar 2.

Menurut Andayani (2007) sebuah objek dan daya tarik wisata tergantung pada empat faktor pendukung, yaitu: atraksi wisata (attraction) adalah segala sesuatu yang menarik minat wisatawan untuk berkunjung ke suatu objek, aksesibilitas (accessibility) adalah tersedianya sarana dan prasarana yang digunakan wisatawan dari dan menuju ke suatu daerah tujuan wisata, fasilitas (facilities) adalah semua fasilitas yang mendukung aktifitas wisatawan selama tinggal dan menuju daerah tujuan wisata, fasilitas tersebut dapat berupa akomodasi, restoran, fasilitas komunikasi dan organisasi kepariwisataan. Selanjutnya, Romani (2006) dan PHKA (2003) menyatakan bahwa daya tarik merupakan faktor yang membuat orang berkeinginan untuk mengunjungi dan melihat secara langsung tempat yang mempunyai daya tarik tersebut. Daya tarik merupakan komponen kajian untuk mengetahui gambaran bentuk-bentuk kegiatan rekreasi yang sesuai dengan sumber daya yang tersedia. 

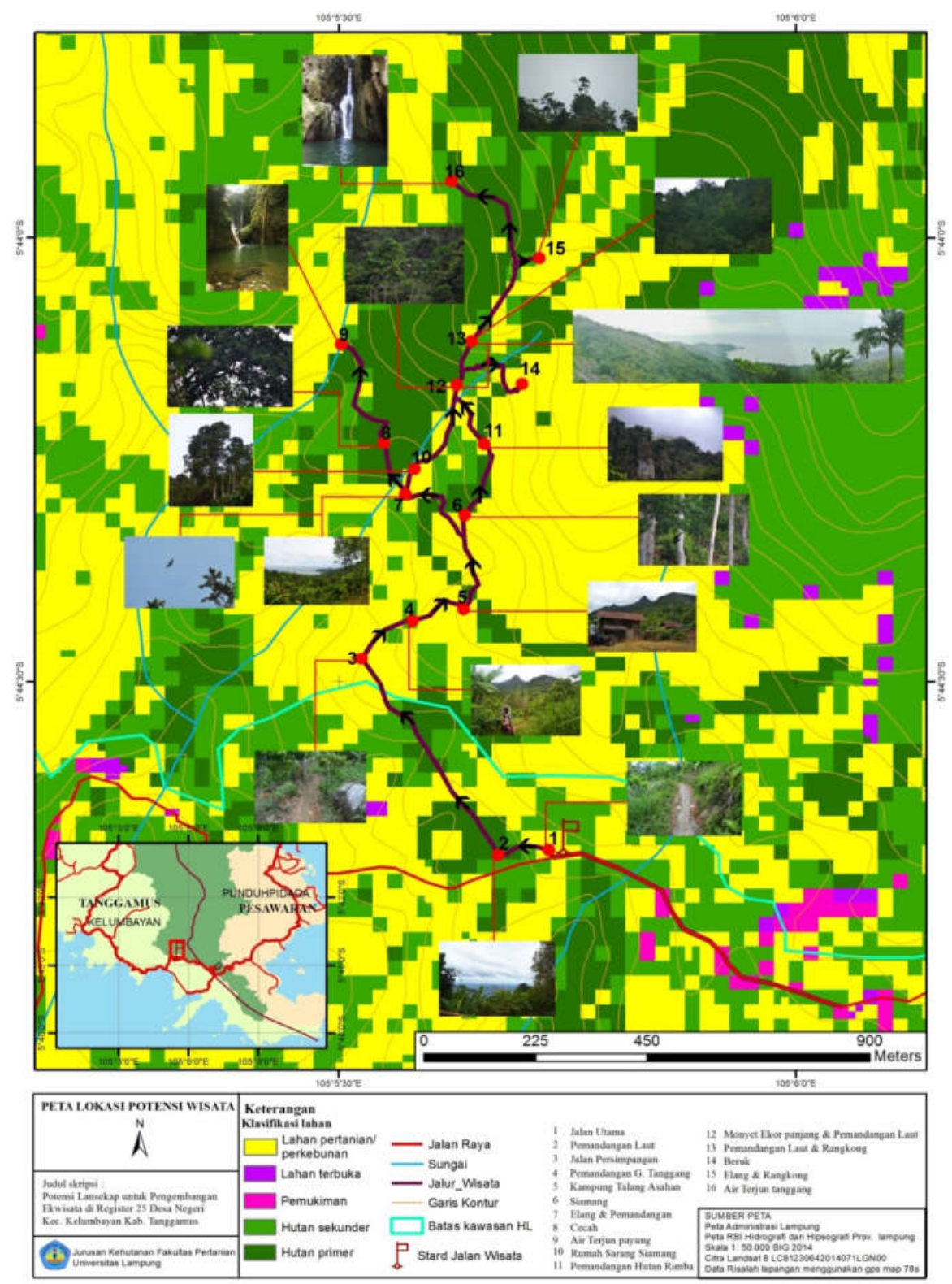

Gambar 2.Peta potensi lansekap.

Panorama yang indah di Register 25 Pematang Tanggang dapat langsung dinikmati di sepanjang jalur wisata (Gambar 3), sehingga sangat mendukung untuk dijadikan objek wisata bagi penikmat alam/panorama dan fotografer. Lokasi ini berada pada ketinggian $804 \mathrm{mdpl}$ dengan suhu berkisar $\pm 20 \mathrm{C}^{0}$. Berjarak sekitar $\pm 700 \mathrm{~m}$ dari Air Terjun Tanggang, atau $\pm 1 \mathrm{~km}$ dari Air Terjun Payung. Area ini memiliki luas sekitar $\pm 20 \mathrm{~m}^{2}$ dengan topografi miring. Pada bagian sisi-sisi lokasi, terdapat pemandangan bentang alam berupa lereng perbukitan yang hijau dan lahan kelola masyarakat sekitar hutan, di lokasi ini pula calon pengunjung dapat menikmati matahari saat terbenam dengan pemandangan Teluk Kiluan, Pantai Batu Suluh beserta pulau disekitarnya pada sore hari. Pada siang hari pengunjung akan dimanjakan dengan pemandangan alam yang hijau dan lautan yang membentang. 


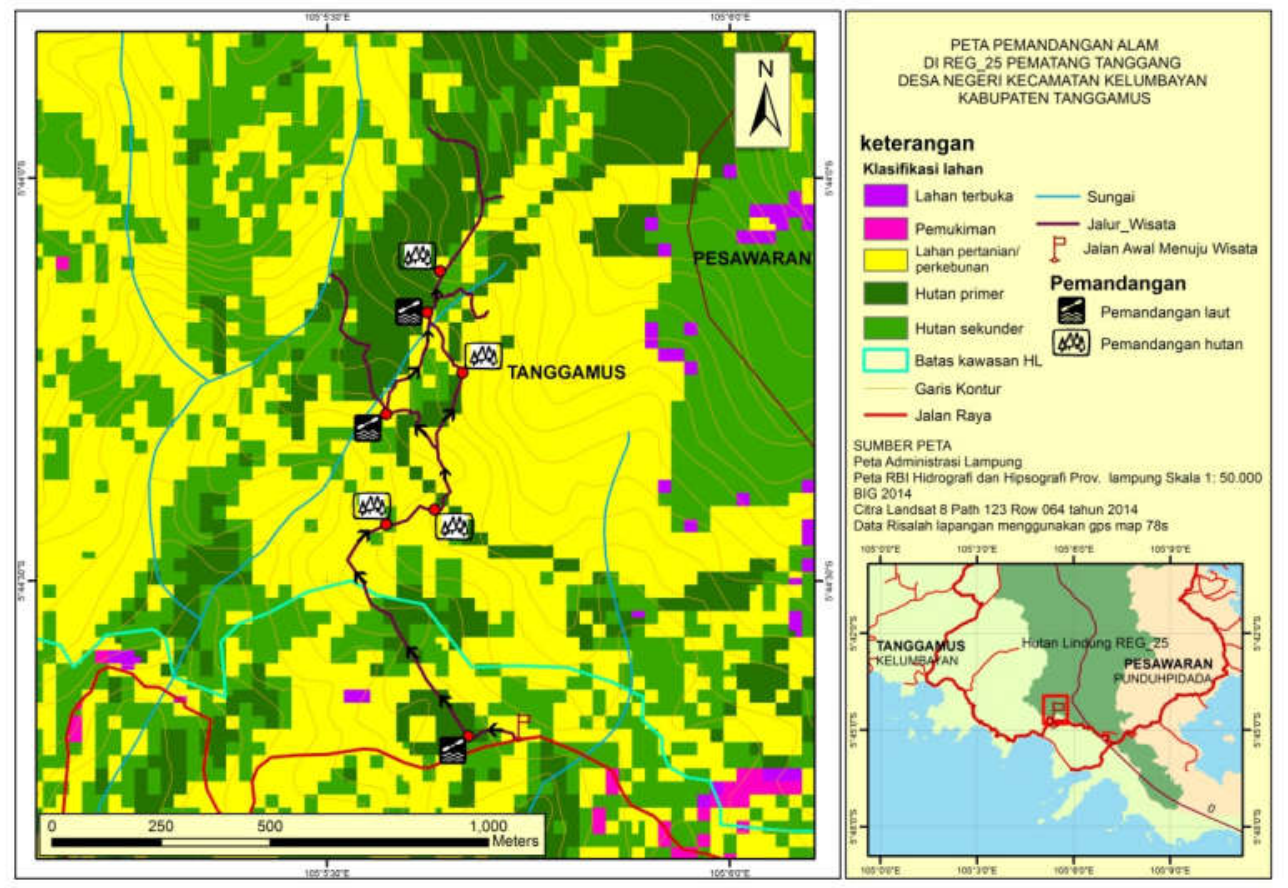

Gambar 3.Lokasi panorama alam.

Air terjun yang terdapat di Register 25 Pematang Tanggang merupakan air terjun yang unik karena memiliki bentuk, keindahan yang terbentuk oleh alam tanpa campur tangan manusia. Air terjun tersebut yaitu Air Terjun Payung, Air Terjun Tanggang dan Curup Rendam serta Curup Lumut. Namun air terjun yang dapat dinikmati keindahannya adalah Air Terjun Payung dan Air Terjun Tanggang, karena akses jalan yang mudah dijangkau. Sedangkan akses jalan menuju air terjun lainnya seperti Curup Rendam dan Curup Lumut cukup sulit dijangkau akibat akses jalan masih tertutup oleh vegetasi yang lebat dan topografi yang cenderung curam berbatu sehingga cukup sulit untuk dilewati.

Komposisi dan struktur vegetasi merupakan komponen habitat yang penting untuk mendukung pengembangan dalam sektor wisata. Komposisi dan struktur vegetasi berpengaruh pada ketertarikan pengunjung untuk menikmati wisata alam. Jenis flora yang dapat dijumpai di sepanjang jalur wisata alam areal hutan di kawasan ini cukup beranekaragam. Jenis-jenis flora yang terdapat di hutan primer disajikan pada Tabel 1 sebagai berikut.

Tabel 1. Jenis flora yang terdapat di hutan primer

\begin{tabular}{cll}
\hline No & Nama daerah & Nama ilmiah \\
\hline 1. & Randu hutan & Bombax ceiba L. \\
2. & Rotan & Calamus sp \\
3. & Bergedat & Ficus Microcarpa \\
4. & Pulai putih & Alstonia pneumatophore \\
5. & Pulai hitam & Alstonia angustiloba \\
6. & Menggris & Koompassia excels \\
7. & Jalatong & Dyera castula Hook \\
8. & Rasamala & Altingia excels \\
9. & Bendo & Artocarpus elasticus \\
10. & Pisang hutan & Musa acuminta \\
11. & Rambutan hutan & Nephelium mutabile \\
12. & Pakis hutan & Alsophila glauca \\
13. & Anggrek hutan & Cymbidium canaliculatum \\
\hline
\end{tabular}


Selain di hutan primer, tanaman yang terdapat dihutan sekunder juga beragam. Jenis flora yang terdapat di hutan sekunder di Register 25 Pematang Tanggang disajikan pada Tabel 2 sebagai berikut.

Tabel 2. Jenis flora yang terdapat di hutan sekunder

\begin{tabular}{rll}
\hline No & Nama daerah & Nama ilmiah \\
\hline 1. & Nangka & Artocarpus heteerophyllus \\
2. & Durian & Durio zibethinus \\
4. & Tangkil/Melinjo & Gnetum gnemon \\
5. & Cengkeh & Syzygium aromaticum \\
6. & Coklat & Theobroma cacao \\
7. & Kopi & Coffea robusta \\
8. & Petai & Parkia speciose \\
9. & Jengkol & Phitecellebium lobatum \\
10. & Pala & Myristica fragrans \\
11. & Dadap & Erythrina lithosperma \\
12. & Johar & Cassia siamea \\
13. & Jambu air & Syzigium aqueum \\
14. & Kemiri & Aleurites mollucana \\
15. & Bambu betung & Dendrocalamus asper \\
16. & Alpukat & Persea Americana \\
17. & Jabon & Anthocephalus chinensis \\
18. & Pulai & Alstonia scholaris \\
19. & Jambu biji & Psidium guajava \\
\hline
\end{tabular}

Berdasarkan hasil pengamatan di lapangan satwa liar yang dapat dijumpai pada pagi hari pukul 07.00-09.00 WIB adalah Siamang (Hylobatus syndactilus), Cecah (Presbytis melalophos), Beruk (Macaca namestrina), Monyet ekor panjang (Macaca fascicularis) dan Tupai (Lariscus insignis) serta jenis burung kutilang (Pycnonotus aurigaster) dan Elang family (Accipitridae). Satwa liar yang dapat dijumpai pada siang hari pukul 11.00-13.00 adalah Julang emas (Aceros undulates), Beruk (Macaca namestrina), Cucak kutilang (Pycnonotus aurigaster), Elang paria (Milvus migrans), Cucak kuning (Pycnonotus melanicterus), sedangkan pada sore hari pukul 15.00-17.00 adalah Siamang (Hylobatus syndactilus), Cecah (Presbytis melalophos) dan Cirik Kumbang (Nyctyornis amictus) serta Rangkong family (Bucerotidae). Informasi dari masyarakat sekitar hutan, bahwa masih banyak satwa liar yang terdapat di Register 25 Pematang Tanggang yang dilindungi. Jenis satwa liar yang dapat dijumpai disepanjang jalur wisata yaitu primata dan burung yang dilindungi oleh Undang-Undang No. 5 Tahun 1990 tentang Konservasi Sumber Daya Alam Hayati dan Ekosistemnya. Peta perjumpaan primata disajikan pada Gambar 4, sedangkan peta perjumpaan burung disajikan pada Gambar 5 .

Penilaian terhadap objek wisata dengan menggunakan foto-foto hasil dokumentasi berupa panorama alam dan air terjun, pemandangan yang indah serta flora dan fauna yang terdapat di Register 25 Pematang Tanggang yang dapat dikembangkan menjadi ekowisata. Penilaian responden dibagi menjadi tiga kategori yaitu baik, sedang dan buruk terhadap foto yang menjadi objek wisata di lokasi penelitian. Responden dalam penelitian ini adalah 30 wisatawan yang berada di Pantai Pahawang Kab.Pesawaran. Adapun hasil dari penilaian responden dapat dilihat dalam Tabel 3 di bawah. 


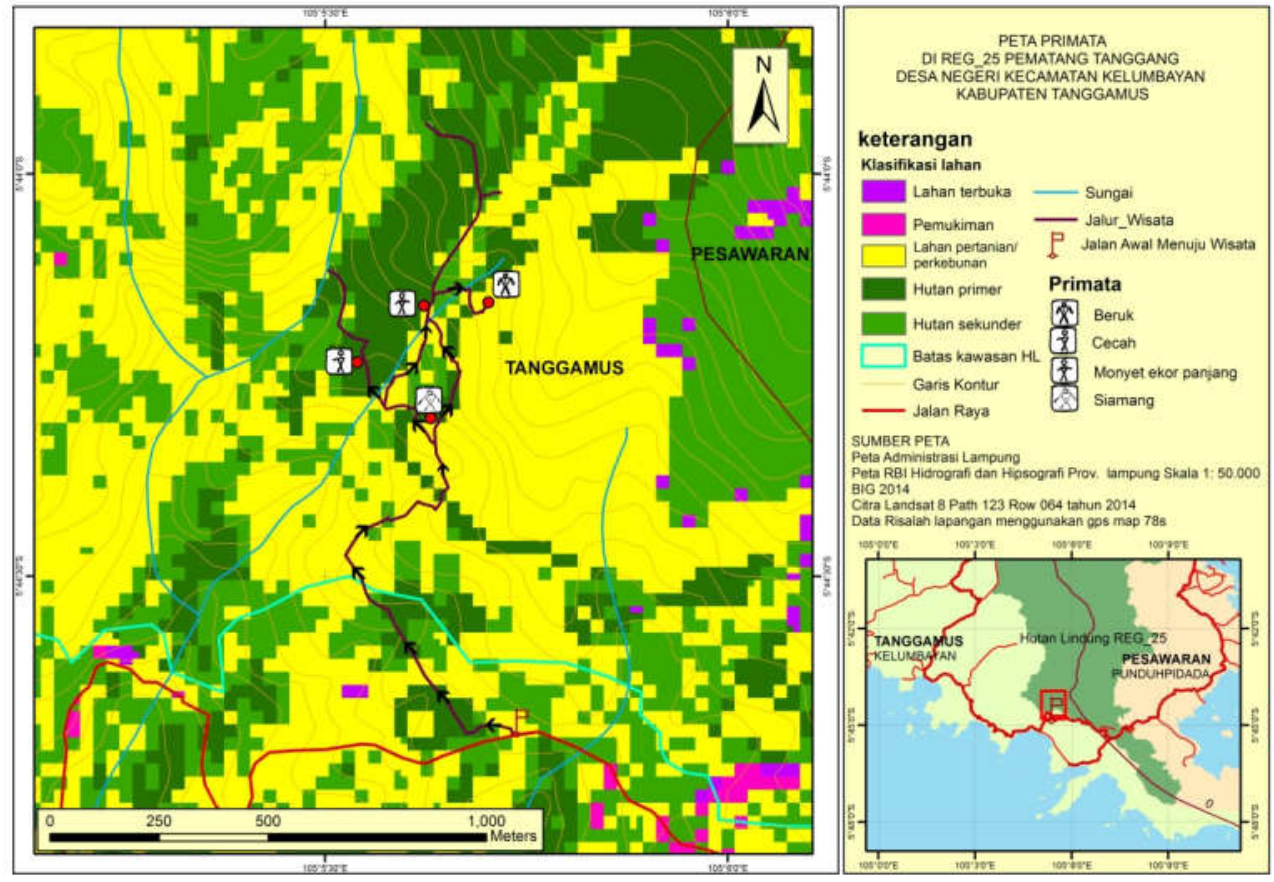

Gambar 4. Peta perjumpaan primate.

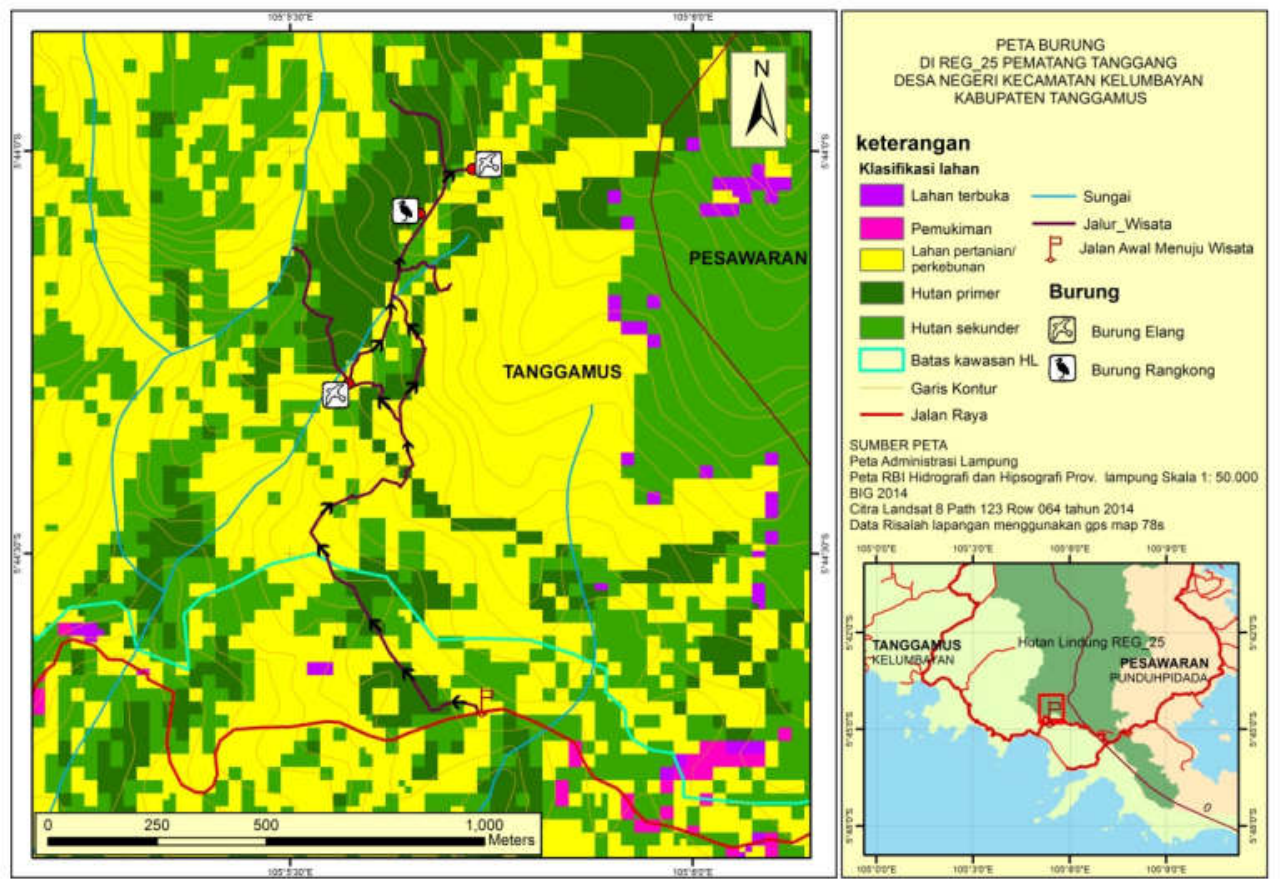

Gambar 5.Peta perjumpaan burung. 
Tabel 3. Hasil penilaian wisatawan terhadap potensi lansekap untuk ekowisata di Register 25 Pematang Tanggang.

\begin{tabular}{ccccccc}
\hline \multicolumn{2}{c}{$\begin{array}{c}\text { Pengetahuan tentang } \\
\text { ekowisata }\end{array}$} & \multicolumn{2}{c}{ Penilaian terhadap potensi lansekap } & \multicolumn{2}{c}{ Pengembangan objek wisata } \\
\hline Tahu & Tidak tahu & Bagus & Sedang & Buruk & Setuju & Tidak setuju \\
\hline $13,33 \%$ & $86,67 \%$ & $85,55 \%$ & $13,89 \%$ & $0,56 \%$ & $100 \%$ & $0 \%$ \\
\hline
\end{tabular}

Sumber : Data Primer 2016.

Berdasarkan Tabel 3 diketahui bahwa 13,33\% wisatawan tahu dan 86,67\% tidak tahu mengenai wisata di Register 25 Pematang Tanggang. Ketidaktahuan tersebut dikarenakan sebagian wisatawan yang menjadi responden terbatas informasi mengenai wisata di Register 25. Sehingga wisatawan yang berasal dari dalam maupun luar wilayah Lampung lebih memilih tempat wisata yang sudah terpublikasi. Penilaian wisatawan terhadap objek wisata berupa pemandangan laut, Gunung Tanggang, Teluk Kiluan, Pantai Suluh, Air Terjun, serta keberadaan flora dan fauna yaitu $85,55 \%$ wisatawan memberikan penilaian bagus, $13,89 \%$ sedang, $0,56 \%$ buruk. Dengan demikian dapat dikatakan bahwa objek wisata yang terdapat di hutan lindung Register 25 Pematang Tanggang Desa Negeri Kec. Kelumbayan Kab. Tanggamus termasuk berpotensi untuk dikembangkan menjadi ekowisata. Hal ini juga dibuktikan dengan $100 \%$ responden setuju untuk dikembangkan menjadi ekowisata. Ketertarikan wisatawan terhadap ekowisata berpengaruh sangat baik untuk pengembangan wisata yang ada di Register 25 Pematang Tanggang Desa Negeri Kec. Kelumbayan Kab. Tanggamus.

Hasil wawancara kepada masyarakat adalah masyarakat mendukung adanya kegiatan pengembangan ekowisata di Register 25 dan menyatakan siap untuk berpartisipasi sesuai dengan kemampuan SDM mereka. Bentuk partisipasi masyarakat adalah partisipasi dalam setiap pelaksanaan kegiatan ekowisata dan perjalanan prosesnya serta dalam pembagian keuntungan ekonomi (seperti dalam Jain, 2000). Masyarakat secara umum ingin secara langsung terlibat dalam setiap proses pelaksanaan kegiatan ekowisata dan menginginkan adanya bimbingan atau pendampingan pada awalnya. Pendampingan pada masyarakat dapat dilakukan pada kegiatan-kegiatan yang mendukung pengembangan ekowisata berbasis masyarakat seperti pendampingan dalam hal pembuatan dan pemasaran souvenir, bahasa Inggris dasar, etika pelayanan, manajemen, akuntansi sederhana untuk warung, identifikasi jenis-jenis flora dan fauna dan inventarisasi Objek Daya Tarik Wisata Alam (ODTWA).

Setiap tindakan manusia digerakkan dan dilatarbelakangi oleh motif tertentu (Suhaidin, 2008). Hasil responden menjelaskan bahwa alasan masyarakat untuk mendukung adanya pengembangan ekowisata di Register 25 adalah untuk meningkatkan taraf hidup masyarakat itu sendiri. Masyarakat mempunyai persepsi bahwa apabila kawasan Register 25 terkenal maka makin banyak wisatawan yang datang ber-kunjung dan pendapatan masyarakat pun akan ikut bertambah. Minat masyarakat untuk berpartisipasi dalam pengembangan ekowisata di Register 25 bermacam-macam seperti jasa transportasi, membuka warung, pemandu wisata, membuka homestay dan menjadi penjaga parkir serta berjualan souvenir.

Aksesbilitas menuju Desa Negeri dapat ditempuh melalui Kota Bandar Lampung dengan menggunakan kendaraan roda empat maupun roda dua. Kendaraan umum hanya mencapai Desa Piabung Kecamatan Padang Cermin \pm 2 jam perjalanan dari Bandar Lampung, kemudian perjalanan dilanjutkan dengan kendaraan roda dua yakni jasa ojek yang tersedia dipersimpangan Desa Piabung Kecamatan Padang Cermin. Dari Desa Piabung menuju Desa Negeri dapat ditempuh melalui dua akses jalan yakni jalan menuju Kecamatan Kelumbayan dan jalan menuju Kecamatan Punduh Pidada seperti dalam Gambar 7. 


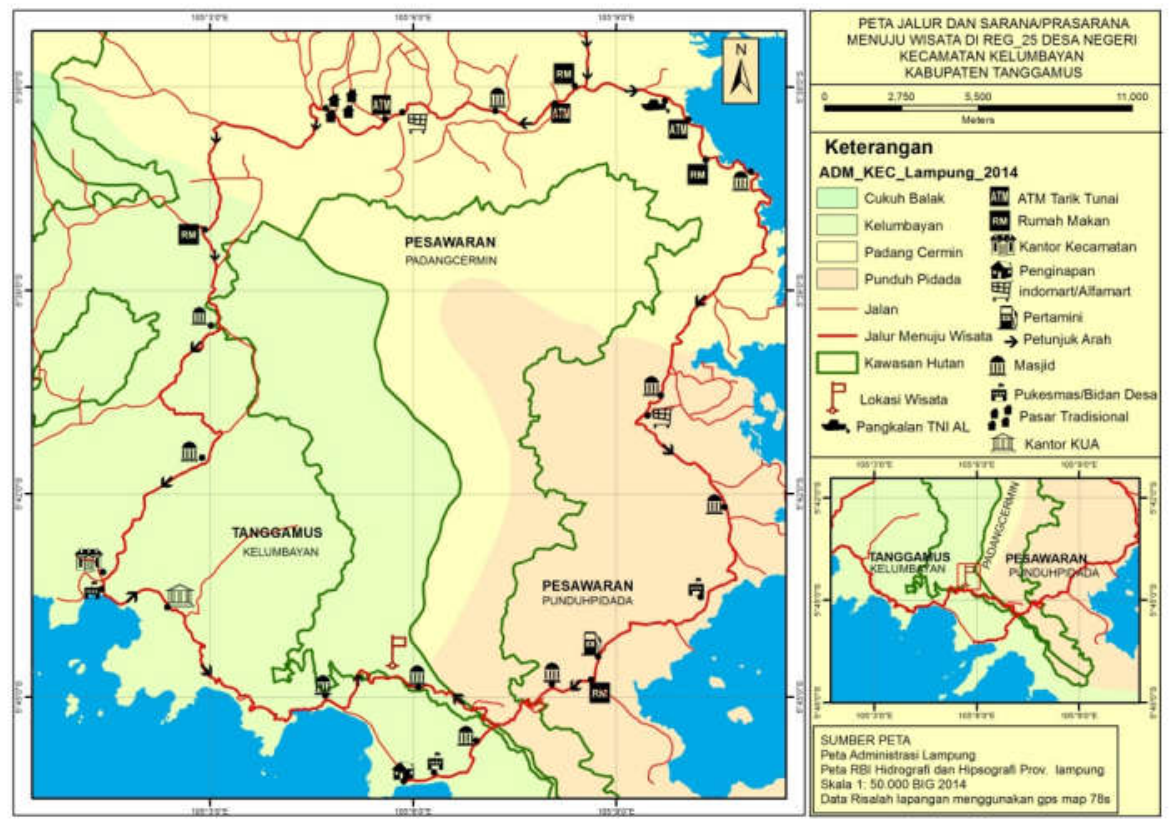

Gambar 7. Peta jalur akses menuju objek wisata.

Aksesbilitas menuju Desa Negeri Kelumbayan dapat ditempuh melalui Kota Bandar Lampung dengan menggunakan kendaraan roda empat maupun roda dua.Aksesibilitas menuju Desa Negeri Kelumbayan dijelaskan pada Tabel 4 berikut.

Tabel 4.Aksesbilitas menuju Desa Negeri Kelumbayan.

\begin{tabular}{llccl}
\hline \multicolumn{1}{c}{ Asal } & \multicolumn{1}{c}{ Tujuan } & Jarak $(\mathbf{k m})$ & Waktu (jam) & \multicolumn{1}{c}{ Kendaraan } \\
\hline Bandar Lampung & Hanura & 27 & 1 & Kendaraan roda 4/umum \\
Hanura & Padang Cermin & 13 & 0,5 & Kendaraan roda 4/umum \\
Padang Cermin & Piabung & 10 & 0,5 & Kendaraan roda 4/umum \\
Piabung & Pasar Bawang & 32 & 1,5 & Kendaraan roda 4/umum \\
Pasar Bawang & Desa Negeri Kelumbayan & 7 & 0,5 & Kendaraan roda 4/umum \\
\hline
\end{tabular}

Fasilitas kesehatan di Desa Negeri Kelumbayan tergolong belum cukup memadai, dengan jumlah penduduk 2745 jiwa hanya terdapat 4 posyandu dan 3 bidan desa. Puskesmas (Pusat Kesehatan Masyarakat) terdekat berada di Pasar Bawang yang berjarak $7 \mathrm{~km}$ yang dapat ditempuh dalam waktu 30 menit dari Desa Negeri Kelumbayan. Obat-obatan yang tersedia di puskesmas pembantu hanya berupa obat-obatan untuk mengobati sakit ringan dan juga pertolongan pertama pada kecelakaan.

Fasilitas ibadah di desa ini tergolong cukup memadai. Terdapat 6 buah masjid dan 4 mushola yang tersebar di setiap dusun. Kondisi masjid bersih dan terawat, kebutuhan air tercukupi.Apabila tidak ada tempat menginap di Desa Negeri, diizinkan untuk menginap di masjid dengan persetujuan pengurus masjid. Desa Negeri Kelumbayan relatif aman, tetapi alangkah baiknya apabila wisatawan lebih waspada dalam melindungi barang berharga miliknya.

Masyarakat desa ini sebagian masih menggunakan sungai, sebagian ada yang sudah memakai MCK. Sedangkan untuk mandi dan mencuci masyarakat menggunakan air dari sumber mata air di dalam kawasan Pematang Tanggang yang dialirkan ke dalam bak penampungan yang disediakan. Sebagian besar masyarakat sudah memiliki bak penampung untuk menampung air yang dialirkan melalui pipa atau selang menuju rumah warga.

Desa ini memiliki enam buah rumah makan, jenis makanan yang dijual antara lain nasi, sayur, lauk berupa ayam, ikan, dan telor, soto, pecel, dan nasi goreng, dua buah warung 
bakso dan mie ayam serta satu buah warung sate. Harga makanan yang dijual cukup bervariasi namum masih terjangkau yaitu berkisar Rp 5.000,00-Rp 20.000. Umumnya rumah makan mulai buka pukul 07.00 WIB sampai dengan pukul 22.00 WIB.

Desa ini berjarak $\pm 89 \mathrm{~km}$ dari Kota Bandar Lampung. Dari Kota Bandar Lampung menuju Desa Punduh Pidada dan Piabung sudah tersedia jalan aspal dengan lebar empat meter. Jalan dari Desa Punduh Pidada menuju Desa Negeri Kelumbayan sudah berupa aspal namun banyak yang rusak, berlubang, dan tidak rata lagi, tetapi saat ini jalan tersebut dalam proses perbaikan. Dari Desa Negeri Kelumbayan ke Pematang Tanggang hanya tersedia jalan setapak berukuran dua meter yang sebagian jalan sudah diperkeras. Desa ini memiliki 6 jembatan dengan konstruksi beton. Semua jembatan masih dalam kondisi baik dan digunakan oleh masyarakat dengan semestinya. Meskipun jembatan dalam kondisi baik, namun tetap memerlukan perawatan untuk bisa bertahan lebih lama.

Air yang mengalir bersumber dari mata air yang terdapat di dalam kawasan Register 25 Pematang Tanggang dipergunakan oleh masyarakat untuk kehidupan sehari-hari. Masyarakat membuat bak penampung kemudian disalurkan melalui pipa ke bak penampungan yang ada di rumah-rumah masyarakat. Pasokan listrik di Desa Negeri Kelumbayan berasal dari Perusahaan Listrik Negara (PLN). Wilayah Desa Negeri Kelumbayan sebagian besar telah dijangkau jaringan listrik PLN tetapi di beberapa tempat masih ditemui masyarakat yang memanfaatkan aliran sungai untuk microhidro yang dibangun secara swadaya oleh masyarakat. Cara kerjanya adalah mengalirkan air melalui pipa untuk memutar turbin yang diletakkan di pinggir sungai. Semakin miring pipa maka arus air akan semakin deras sehingga energi listrik yang dihasilkan akan semakin besar. Satu turbin bisa menerangi 4 sampai 14 rumah. Sebagian masyarakat juga ada yang menggunakan Tenaga Surya sebagai alat penerangan. Tetapi Tenaga Surya hanya bisa digunakan pada satu rumah dan lampu yang dipakai tidak lebih dari 3 buah lampu.

Fasilitas kebersihan di desa ini tergolong kurang memadai. Pada umumnya masyarakat membuang sampah dan limbah dengan cara menggali lubang berukuran persegi panjang dengan jarak 5-6 meter dari rumah sebagai tempat pembuangan sampah rumah tangga. Setelah sampah memenuhi lubang tersebut biasanya masyarakat akan membakarnya.

Akomodasi di desa ini tergolong kurang memadai, karena penginapan yang terdapat hanya di pinggir Pantai Kiluan. Salah satu alternatif akomodasi yang dekat dengan lokasi wisata adalah rumah penduduk yang ditawarkan secara sukarela dan areal topografi datar yang bisa dimanfaatkan sebagai tempat untuk berkemah.

\section{SIMPULAN DAN SARAN}

Simpulan yang diperoleh dari penelitian potensi lansekap untuk pengembangan ekowisata di Hutan lindung Register 25 Pematang Tanggang Kelumbayan Kabupaten Tanggamus adalah sebagai berikut.

1. Potensi yang terdapat di Register 25 Pematang Tanggang Desa Negeri Kecamatan Kelumbayan Kabupaten Tanggamus berupa bentang alam panorama yang indah berupa pemandangan Teluk Kiluan, Pantai Batu Suluh dan Gunung Tanggang. Selain itu juga memiliki air terjun yang menawarkan keunikan dan keindahan serta jenis flora dan fauna langka yang masih dapat dijumpai di sepanjang jalur menuju air terjun.

2. Penilaian wisatawan terhadap objek wisata berupa pemandangan alam Teluk Kiluan, Pantai Batu Suluh, Gunung Tanggang, Air Terjun, serta keberadaan flora dan fauna yaitu $85,55 \%$ bagus, $13,89 \%$ sedang, dan $0,56 \%$ buruk.

3. Masyarakat $100 \%$ mendukung pengembangan ekowisata di Register 25 Pematang Tanggang. Bentuk partisipasi masyarakat dalam kegiatan pengembangan ekowisata adalah secara langsung terlibat dalam pelaksanaan kegiatan ekowisata dan sharing profit. 
Saran yang didapat dari penelitian ini adalah (1) perlu adanya publikasi terkait ekowisata yang terdapat di Register 25 Desa Negeri Kecamatan Kelumbayan Kabupaten Tanggamus kepada khalayak ramai atau calon wisatawan yang ingin berkunjung; (2) Perlu adanya sosialisasi lebih lanjut kepada masyarakat setempat mengenai objek wisata di Register 25 Pematang Tanggang Kabupaten Tanggamus yang dapat dikembangkan sebagai ekowisata; dan (3) perlu adanya penelitian lebih lanjut mengenai perencanaan pengembangan ekowisata di Register 25 Desa Negeri Kecamatan Kelumbayan Kabupaten Tanggamus.

\section{DAFTAR PUSTAKA}

Andayani, N. L. H. 2007. Pengembangan obyek wisata Desa Tihingan, Kecamatan Banjarangkan, Kabupaten Klungkung.Jurnal Manajemen Pariwisata. 7(7) : 41-58.

Jain, N., W. Lama., dan R. Lepcha. 2000. Community-based Torism for Conservation and Development: A Resource Kit. The Mountain Institute. Washington, USA. 123 pp

Kerlinger, F. N. dan Lee, H. B (2000).Foundation of Behavioral Research (Fourth Edition). USA: Holt, Rainner \& Winston, Inc. 890 pp.

Khakhim, N. 2008. Analisis preferensi visual lanskap pesisir daerah istimewa yogyakarta untuk pengembangan pariwisata pesisir menuju pada pengelolaan wilayah pesisir berkelanjutan.Jurnal Forum Geografi. 22(1): 44-59

Nugroho, Iwan. 2011. Ekowisata dan Pembangunan Berkelanjutan. Buku. Pustaka Pelajar. Yogyakarta.362 pp.

Perlindungan Hutan dan Konservasi Alam.2003. Pedoman Analisis Daerah Operasi Obyek dan Daya Tarik Wisata Alam (ADO-ODTWA). Direktorat Jenderal Perlindungan Hutan dan Konservasi Alam. Bogor.

Romani, S. 2006. Penilaian Potensi Obyek dan Daya Tarik Wisata Alam Serta Alternatif Perancangannya di Taman Nasional Bukit Dua Belas Provinsi Jambi. Skripsi. Institut Pertanian Bogor. Bogor. 91 pp.

Sudiarta, M. 2006. Ekowisata hutan mangrove : wahana pelestarian alam dan pendidikan lingkungan. Jurnal Manajemen Pariwisata. 5(1) : 4-25

Suhaidin, Tahaimin. 2008. Artikel Motivasi dan Pembangunan Diri: Definisi, Pengertian, dan Motivasi Takrifan Motivasi. http://www.ugmc.bizland.com/ak-

ertimotivasi.htm.Diakses pada 18 maret 2015. 